\title{
Ugandan effort to constrain HIV spread hampered by systemic and cultural obstacles to male circumcision
}

$\mathrm{T}$ he president of the country once scoffed at the notion. mately prove counterproductive because it may persuade some men to take fewer precautions during sex.

Others say the country's primitive health care system compounds the problem. The system lacks the resources and the capacity to implement a nation-wide program, while the procedure, when it is performed as part of tribal rituals, is often botched because it is undertaken with unsterilized and unspecialized instruments.

Yet, the World Health Organization (WHO) recommends it as an HIV prevention strategy and clinical trials indicate that, on average, the procedure could reduce men's risk of contracting HIV from females by up to $60 \%$ (Lancet 2007;369:657-66 and Lancet 2007;369;643-56 and PLoS Med 2005; 2[11]:e298).

Such is the controversy surrounding male circumcision in Uganda, where President Yoweri Museveni last year rebuked claims that circumcised men are less likely to contract HIV/AIDS but where the government plans to introduce circumcision as an HIV strategy.

Government health officials are banking on existing cultural practices to push the strategy into other parts of the country as it seeks to curb the spread of HIV, which the World Health Organization in 2005 estimated infects 6304 of every 100000 Ugandans over the age of 14 . A projected 1 million Ugandans now live with the virus. Circumcision has long been practised by the Bagisu tribe in Eastern Uganda on boys aged 12-18 as an initiation into manhood. This year, an estimated 3000 boys will undergo the "Imbalu" ceremony during circumcision season (July-January).

Health authorities say their studies indicate that even communities with no history of the practice will be amenable to circumcision of their youths. "Acceptance is high but we have to bring the services to the small health centers

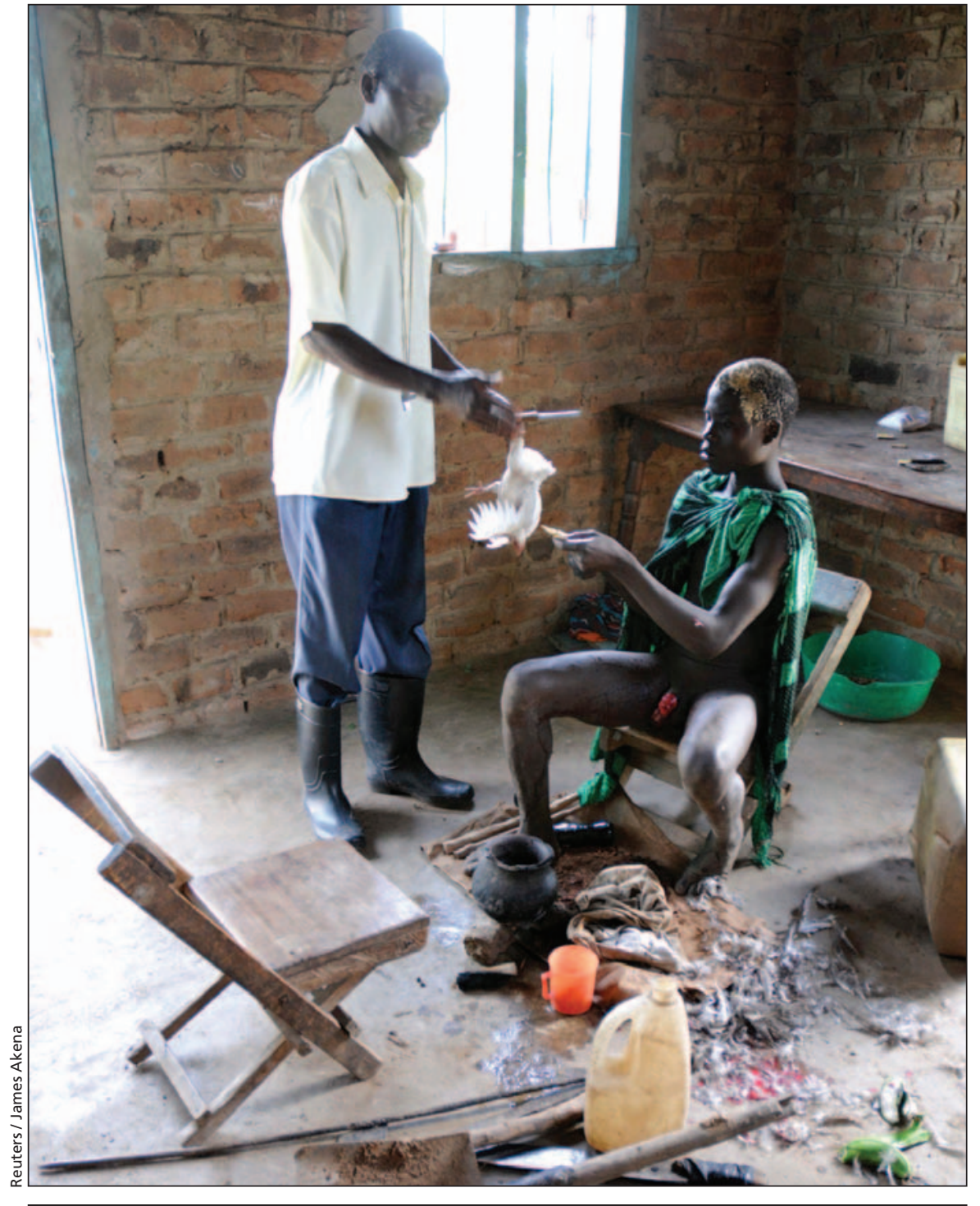

A Bagisu traditional surgeon performs cleansing rituals on 1 of over 300 initiates who participated in a circumcision ritual in August marking their transition from childhood to adulthood.

for easy accessibility in order to get a good turn out." says Dr. Alex Opio, an official at the National Disease Control Department which is charged with developing the program.

WHO projects that the introduction or scaling-up of circumcision services will have a huge effect on HIV prevention, noting that full circumcision coverage could avert about 5.7 million new infections in the next 20 years in subSaharan Africa. But Uganda's circumcision rate among males between 14 and 49 remains one of the lowest in sub-Saharan Africa at about $25 \%$.

But systemic problems may undermine the Ugandan effort. According to a ministry of health analysis, a shortage of health workers is an obstacle. Uganda's health worker figures remain low at one physician per 1000 populations. Most workers trained leave the country for better pay, especially to South Africa and Britain.

"Although circumcision is a minor operation and most trained health 
workers can carry it out, their numbers are still low," says Dr. Innocent Nuwagira, a national professional officer on HIV at WHO in Kampala. "Our health facilities are already overloaded. Unlike [treating] illnesses, circumcision is optional and therefore few people will stand the inconvenience [or the] long queues that are common in most health service delivery centres."

Concerns have also been raised that a nation-wide circumcision program could breed complacency and undermine older prevention strategies based on "absti- nence, faithfulness and condom use."

Uganda's Director of Health Services, Dr. Sam Zaramba, says the strategy must be introduced with caution. "This is not a magic bullet. That's what we have to tell people over and over."

Analysts fear that a drop in condom use could be disastrous. Condom use is now projected at just $60 \%$ of the population.

Others are concerned that circumcision program will have a detrimental impact on women, as it could result in an increase in infection rates if couples opt for riskier behaviour like engaging in sex without a condom. "It's all about men, the sexual satisfaction of men ... but what about the women? What is their involvement?" asks Siphiwe Hlope, a founder an AIDS support organization in Swaziland.

But UNAIDS researchers have asserted that HIV acquisition risk among women would decline by $2 \%$ for every $5 \%$ of men circumcised. - Rosebell Kagumire, Kampala, Uganda

DOI:10.1503/cmaj.081761

\section{DISPATCH FROM THE MEDICAL FRONT}

\section{Somali symbiosis, part 1:}

\section{what I saw}

Y ou see first through the filter of your own judgments, so I saw disarray.

I saw a place without a functioning state government, in a steady state of chaos, with little in the way of a health care system, heavily reliant on the 15 projects that Médicins Sans Frontières runs throughout Somalia, like in the one that I worked at during a 3-month stint as a volunteer general surgeon in Beletweyne.

People would present to us from far away, with illnesses and wounds that were advanced, with symptoms from diseases that were entirely treatable, if detected early. Snake bites. Tuberculosis. Appendicitis. Ulcers. Infections that resulted in prolonged courses of care, amputations and loss of life.

I saw pregnant women with high blood pressure, seizures, obstructed labour and undetected twins. Despite the valiant efforts of our excellent Australian midwife and local midwives, these undetected conditions resulted in urgent cesarean sections, destruction of vaginas, preventable hysterectomies, dead babies and families without a mother. The trauma to the birth canal from obstructed and prolonged labour leads to fistulas, and, in turn, to incontinence and complicated social ramifications, often resulting in the mother be-

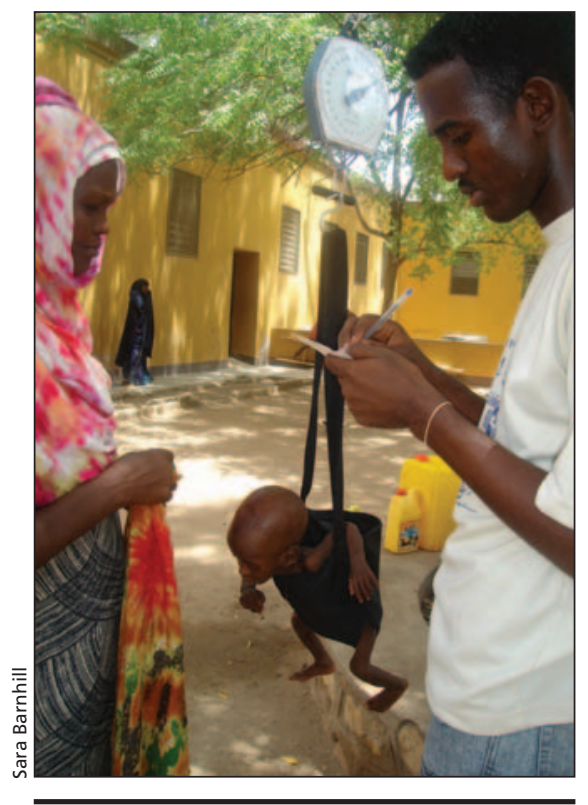

A local physician weighs an infant at the Médicins Sans Frontières clinic in Beletweyne, Somalia.

ing ostracized from the community and rejected by her husband.

I saw the effects of a nonexistent educational infrastructure. Without schools, idle youth have time and cause for frustration and are vulnerable to recruitment for armed conflict, which feeds the community's instability. Most people lacked safe running water, fuel for cooking, electricity and an income. The roads were difficult to pass at the best of times.

The crumbling agricultural and security infrastructure yields predictable outcomes: starvation, malnutrition, frustration, desperation, violence. Curious children often run towards the sounds of gunfire and are maimed. They lift, or jump on, shiny metallic objects and soon have parts of their hands, arms, legs, eyes or genitals blown apart.

I saw people recover from illnesses and injuries that I could not imagine were survivable.

I saw resources stretched far beyond their limits by the thousands of vulnerable people relocated to our area to escape fighting in their hometowns, deposited into massive refugee camps. They were separated from their jobs, from families, from their land and their clans. Their presence is a source of stress in many ways. And there are severe limits to international aid. Other than Médicins Sans Frontières, most humanitarian organizations have withdrawn because of security concerns. - Dr. John Barnhill, Beletweyne, Somalia

DOI:10.1503/cmaj.081666

CMAJ invites contributions to "Dispatches from the medical front," in which physicians and other health care providers offer eyewitness glimpses of medical frontiers, whether defined by location or intervention. Submissions, which must run a maximum 400 words, should be forwarded to: wayne.kondro@cma.ca 